\title{
Big Five Personality Traits on Job Satisfaction Mediated by Procedural Justice
}

\author{
S. Y. Tham and H. M. Wong
}

\section{ABSTRACT}

The aim of this paper is to investigate relations between an isolated dimension of Big Five personality traits and job satisfaction, while considering a mediating effect on this relationship. More specifically, personality traits like Openness to experience, Conscientiousness, Extraversion, Agreeableness and Neuroticism or OCEAN, are treated as antecedents of job satisfaction while procedural justice is considered as mediator in understanding the underlying mechanism. Data was gathered via a questionnaire in a cross-sectional study of Big Five Inventory (44 items), Job Satisfaction Survey (12 items) \& Procedural Justice (9 items). Primary data were collected from 127 hotel front desk managers working in three-star hotels within central region in Malaysia and were analyzed by using SPSS v25 and PLS-SEM v3.2.8. It was found that across the traits, Neuroticism had the strongest relationship with job satisfaction, while Conscientiousness did not have any relationship with job satisfaction. Procedural justice completely mediated the association between Conscientiousness and job satisfaction, but only partially mediated the relationships between Openness to experience, Extraversion, and Agreeableness and job satisfaction. By assessing the Big-Five personality traits as predictors of job satisfaction, this research adds to the body of knowledge and gives crucial information to indicate that organizations should place a greater emphasis on improving employees' justice, which is the underlying relationship between personality and job satisfaction. The findings from this paper may allow organizations related to hotel industry to formulate strategic plans to diminish employee turnover rates while increasing job satisfaction and thus profitability.

Keywords: Big Five Personality Traits, Job Satisfaction, Procedural Justice.

Published Online: November 26, 2021

ISSN: $2736-5522$

DOI: $10.24018 /$ ejsocial.2021.1.6.151

S. Y. Tham

UNITAR International University,

Malaysia.

(e-mail: grace.tham@ ${ }^{\text {gmail.com) }}$

H. M. Wong*

Taylor's University, Malaysia

(e-mail: hoomeng@hotmail.com)

*Corresponding Author

\section{INTRODUCTION}

For an intent of optimizing human resource capacity, job satisfaction acquires importance. This is because it can be seen as an indication of psychological well-being and can contribute to employee behavior that influences the functioning of an organization (Buama, 2019). Job satisfaction is strongly correlated with personality according to Dispositional Approach. It will remain to be constant and stable over time (Judge \& Lanen, 2001). Nevertheless, some researchers found that job satisfaction was impacted by other factors besides personality traits (Cohrs et al., 2006). Nonetheless, results revealed that company should pay attention to improving the procedural justice of workers that was the psychological underpinnings of the link between personality and job satisfaction (Camgoz \& Karapinar, 2011). Hence, mediating function of procedural justice as consequences of personality traits-job satisfaction inter-relations is studied.

Hotel industry registered the highest employee turnover rate in Malaysia (AON Heweiit China HCJ, 2016). Recruitment, training, and development (Nadiri \& Tanova, 2010), cost of replacement, cost of training, and cost of vacancy are all expensive costs for a company with such a high turnover rate (Heydarian \& Abhar, 2011). Recent research shown that overall job satisfaction was found to have a strong negative relationship with the likelihood of leaving the company (Alam \& Asim, 2019). Low job satisfaction is more likely to provide inferior services (Buama, 2019). Employee's personality is crucial because customers may purchase from a competitor owing to better prices or higher quality of service (Julie \& Jacqueline, 2017). Budget hotels (those with a three-star rating or less) saw a $15 \%$ t to $20 \%$ loss in income as a result of online competition. Airbnb, throughout the last two years, according to Malaysia Budget Hotel Association (MyBHA). Employee's turnover had been a major issue as part of every growing industry in the past. This issue will pose a detrimental effect to human resource management of an organization if left unaddressed (Singh \& Amandeep, 2017). 


\section{LITERATURE REVIEW}

Using a model as an organizing framework, this study is linking each dimension of Big Five personality trait, as independent variable (IV), to job satisfaction, as dependent variable (DV), where procedural justice is treated as mediator of the relationship. The theoretical framework is built based on literatures. Early researchers had classified five factors that correlated with job satisfaction, namely: Openness to experience, Conscientiousness, Extraversion, Agreeableness and Neuroticism or known as OCEAN. Facets of job satisfaction included pay, promotion, and supervisor whereas dimensions of procedural justice divided into system justice and rater justice. Conceptual framework as per Fig. 1. Source of the model was adopted and adapted from Five Factor Model by John et al. (1991), Two-dimensional approach by Berrin Erdogan (2001) and Job Satisfaction by Paul Spector (1985).

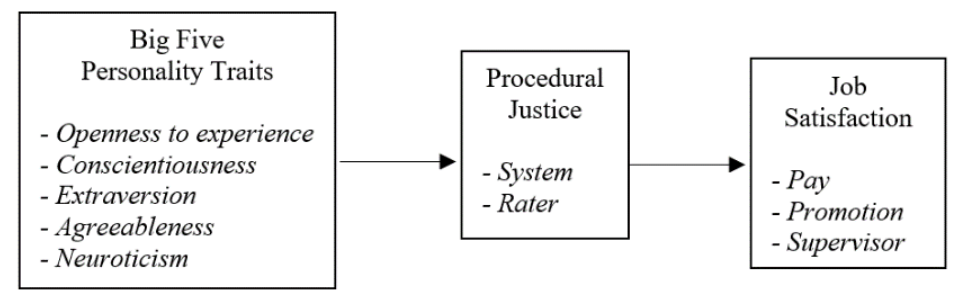

Fig. 1. Conceptual model.

\section{Concepts of Big Five Personality Traits}

A personality trait is a persistent pattern of thinking, feeling, or acting that can be seen across time and in a variety of settings. The Big Five, also known as OCEAN (Openness to Experience, Conscientiousness, Extraversion, Agreeableness, Neuroticism), is a group of five bipolar trait categories that make up the most extensively used personality structure model (Soto, 2018). Big Five personality traits (McCrae \& Costa, 1991) are characterized as:

1. Openness to Experience: divergent thinking, smart, creative, scientific, artistic, and liberal

2. Conscientiousness: accountable, systematic, result oriented, determined. reliable, hardworking and initiator.

3. Extraversion: outgoing, friendly, likeable, socially confident, tendency to concern with external things

4. Agreeableness: kind, cooperative, sympathetic, warm, trusting, and considerate

5. Neuroticism: overanxious, nervous, obsessive, jumpy, compulsive, nervy and full of negative emotions.

\section{CONCEPTS OF JOB SATISFACTION}

Job satisfaction, defined as an individual's overall feeling about their job, has a direct impact on one's personal, social, and organizational life, as well as playing a key role in one's mental and physical health (Golpayegan, 2017). Employees' feelings of contentment at work are referred to as job satisfaction. It is one of the most popular human resource management study topics. It's also become a global issue that many businesses are becoming concerned about (Karnica, 2016). Job satisfaction appears to be linked to pay, promotion and supervision, according to the previous data (Muhammad \& Akhter, 2010). Situational Theory suggested job satisfaction is a result of an individual's personal attributes interacting with organizational characteristics which included pay, promotional opportunities, and supervision (Worrell, 2004).

\section{Concepts of Procedural Justice}

The fairness of methods employed by persons in positions of authority to attain specified outcomes or judgments is characterized as procedural justice (Bennett et al., 2019). It is a condition of a job that is related to an employee's personality will inspire him or her to perform more efficiently since he or she feels at ease with his or her job (Kharismasyah et al., 2017). Procedural fairness is concerned with a decision maker's procedures rather than the actual outcome reached when deciding; it is necessary to follow a fair and proper approach (Ombudsman Western Australia, 2019). 


\section{RELATIONShiP OF Big Five PERSONALity TRAits - Job SATISFACtion}

Employees will find happiness in a work setting that allows them to exhibit their distinct personality qualities, according to the Trait Activation theory (Tett \& Burnett, 2003).

Big Five Model personality appear to be relevant to different culture. Hemantha Kottawatta (2016) and Muhammad and Azhar (2015) reported that this model has been developed to measure the individual personality traits that affect job satisfaction in their research recently in Sri Lanka apparel industry and Pakistan bank industry respectively. Openness to experience, Conscientiousness, Extraversion and Agreeableness were found to have a positive, but Neuroticism had a negative, and significant relationship with manager's job satisfaction from multi-national companies in Philippines (Buama, 2019). Openness to experience, Conscientiousness and Agreeableness were positively and significantly linked to job satisfaction while Neuroticism negatively affected job satisfaction from 7662 people from the United Kingdom were polled in a wide national sample (Bui, 2017).

"Self-Verification theory" explained people would conceive idea themselves, which underpinning correlation for Openness to experience-job satisfaction. A study was conducted by Yildirim (2015) to examine personality traits-job satisfaction linkage among five-star hotel workers in Antalya province, Turkey. A statistically significant Openness to experience -job satisfaction relationship was observed. Extraversion is significantly linked to job satisfaction from 7662 people from the United Kingdom were surveyed in a wide national sample (Bui, 2017). Study found Extraversion had positive influence on satisfaction (Ali, 2018). Findings showed that the most dominant dimension based on Big Five Personality for support staffs in University Technology Malaysia, Johor campus is Agreeableness while Agreeableness was also found to have significant relationship with job satisfaction (Ishak et al., 2018). A weak and negative connection of Neuroticism-job satisfaction, but a positive Extraversion-job satisfaction linkage were found in India, whereas no significant relationships with other personality traits (Rožman et al., 2017).

\section{RElationship OF BIg Five PERSONALITy Traits - Procedural Justice}

The Big Five personality traits of Conscientiousness, Extraversion, Agreeableness, and Neuroticism are likely to be associated with the proximal effect of procedural justice. Individuals' interpersonal tendencies relating to the degree of collaboration, helpfulness, and civility that they have are referred to as Agreeableness (Barrick \& Mount, 1991). According to the literature, businesses prefer to hire people who have unique variations that make them more likely to create creative outputs. As a result, this study investigated how Openness to experience, a construct linked to creative performance, can interact with justice perceptions (Aneika, 2011). Agreeableness and Neuroticism were significant predictors of organizational justice across all categories. Agreeableness was found to be positively connected to procedural justice, but Neuroticism was found to be adversely related (Shi et al., 2009)

\section{RELATIONSHIP OF PROCEDURAL JUSTICE - JOB SATISFACTION}

Justice Theory indicated individual self-perception would determine job satisfaction (Lambert et al., 2005). According to the Social Exchange Theory, people who believe they are being treated unfairly are more likely to be frustrated and unsatisfied (Homans, 1961). Procedural justice perception of the Human Resource practice significantly influenced job satisfaction of Asian managers as a whole group (Yamazaki \& Yoon, 2012). Increased procedural justice better job satisfaction cognition (since it gives employees evidence of their active competence) (Seibert \& Kramer, 2001). Job satisfaction was influenced by three types of organizational justice (distributive, procedural, and interpersonal) (Loi et al., 2009).

\section{Relationship of Big Five Personality Traits - Procedural Justice - Job Satisfaction}

Personality traits require trait-relevant contexts and cues for manifestation, according to the Trait Activation principle. To put it another way, an individual only acts in trait-like ways in situations that are relevant to that trait. As proactive behavior is evoked only under certain cues, the relationship between proactive personality and employee outcomes may vary depending on the environment, according to Trait Activation theory. Such hints can be found in the procedural justice environment (Tett \& Guterman, 2000; Tett \& Burnett, 2003). Relationship between individual level personality variable and pay satisfaction in South Africa is completely mediated by organizational justice perceptions (Bindu et al., 2019). Survey data were collected from Turkey insurance companies' employee, and it was indicated that procedural justice mediated personality traits - job satisfaction correlation (Camgoz \& Karapinar, 2011). 


\section{Methodology}

This study was guided by the following research questions and hypothesis.

1. Is there positive or negative correlation of each personality trait-job satisfaction?

2. Which of the personality trait influenced job satisfaction the strongest?

3. Does procedural justice mediate correlation of each personality trait- job satisfaction?

H1: Openness to experience $(\mathrm{O})$ is positively correlated to job satisfaction (JS)

$\mathrm{H} 2$ : Conscientiousness (C) is positively correlated to JS

H3: Extraversion (E) is positively correlated to JS

H4: Agreeableness (A) is positively correlated to JS

H5: Neuroticism (N) is negatively correlated to JS

H6: Procedural Justice (PJ) is positively correlated to JS

H7: PJ meditates positive relationship between $\mathrm{O}$ and JS

H8: PJ meditates positive relationship between $\mathrm{C}$ and JS

H9: PJ meditates positive relationship between $\mathrm{E}$ and JS

H10: PJ meditates positive relationship between A and JS

H11: PJ meditates negative relationship between $\mathrm{N}$ and JS

This research is quantitative based. A total of 127 front desk managers, who are critical in hotel operations, were randomly selected as sample from central regions Malaysia. Each unit analysis of population will have an equal probability to be included (Bryman \& Bell, 2015). Research instruments used to gather primary data are a self-construct demographic survey, adopted 44-items BFI or Big Five Inventory (John et al., 1991) which comprised five subscales namely Openness to experience, Conscientiousness, Extraversion, Agreeableness and Neuroticism, 12-items Job Satisfaction Scale (Erdogan, 2001). include three subscales like Pay, Promotion and Supervisor and 9-items Two-Dimensional Construct (Spector, 1985). with two subscales i.e., System Justice and Rater Justice. Demographic questionnaire, with a set of fixed options, was created to collect personal details like respondent's gender, age, marital status, highest education background, service tenure and monthly income. Other sections are close-ended questions with a consistent band which used five-point Likert scale with values of 1-5 which ranged from Strongly Disagree-Strongly Agree. For further evidence, secondary data was compiled from multiple materials such as research papers, published journals, articles, book chapters, online resources, conference proceedings and so on.

\section{RESULTS}

TABLE I: DEMOGRAPHIC PROFILES

\begin{tabular}{cccc}
\hline \hline Variables & Level & Frequency & $\%$ \\
\hline \multirow{2}{*}{ Gender } & Male & 71 & 55.9 \\
& Female & 56 & 44.1 \\
& $21-25$ & 9 & 7.1 \\
Age & $26-30$ & 48 & 37.8 \\
& $31-35$ & 44 & 34.6 \\
& $36-39$ & 4 & 3.1 \\
Marital Status & 40 years \& above & 22 & 17.3 \\
& Single & 77 & 60.6 \\
Education & Married & 50 & 39.4 \\
& Diploma & 50 & 39.4 \\
& Bachelor & 38 & 29.9 \\
& Master & 39 & 30.7 \\
Working Experience & $1-5$ years & 60 & 47.2 \\
& 6-10 years & 29 & 22.8 \\
& $11-15$ years & 19 & 15 \\
& 20 years \& above & 19 & 15 \\
Income Per Month & Less than RM 2,500 & 16 & 12.6 \\
& RM 2,051 - RM 4,000 & 49 & 38.6 \\
& RM 4,001 - RM 6,000 & 31 & 24.4 \\
& RM 6,001 \& above & 31 & 24.4 \\
\hline \hline
\end{tabular}

The Google form, email, personal collection were the primary data collection methods that was used in this research. SPSS v25 was used to analyze demographic profile of respondents and descriptive statistic of study variables. Smart Partial Least Square (PLS) version 3.2.8 system was used to test the hypotheses. The initial analyses of the data include data processing and checking for missing values, normality assumption, outlier detection and multicollinearity followed by discussing the results of common method bias. Data processing includes the steps of data checking, editing, and coding to ensure the data obtained 
are reasonably good (Sekaran \& Bougie, 2010).

The basic demographic characteristics of the sample are shown in Table I. The vast majority of those who responded were male $(55.9 \%)$. For age group, $37.8 \%$ or majority ranged from 26 to 30 and they are single. Most of the respondents are diploma holder and in view of working experience, $47.2 \%$ or most of the respondents have job tenure of 1 to 5 years only. Employee monthly income mainly ranged from RM 2,501 to RM 4,000.

Table II presents the results of mean and standard deviation for each construct in the model study. The result showed that all the variables in this survey have a mean and a standard deviation, whereby most of the 5 Likert scales variables are more than 3 except for Neuroticism.

TABLE II: DESCRIPTIVE STATISTICS SUMMARY OF STUDY VARIABLES

\begin{tabular}{cccccc}
\hline & $\mathrm{N}$ & Minimum & Maximum & Mean & Std. Deviation \\
\hline JS & 127 & 1.58 & 4.25 & 3.0098 & 0.63678 \\
PJ & 127 & 1.67 & 4.56 & 3.0962 & 0.82383 \\
OP & 127 & 1.50 & 4.70 & 3.5323 & 0.66522 \\
CON & 127 & 1.89 & 4.67 & 3.5293 & 0.66246 \\
EX & 127 & 2.00 & 4.75 & 3.5000 & 0.70676 \\
AG & 127 & 1.56 & 4.67 & 3.0516 & 0.70033 \\
NEU & 127 & 1.13 & 4.38 & 2.8150 & 0.81114 \\
Valid N (listwise) & 127 & & & & \\
\hline \hline
\end{tabular}

According to Hair et al. (2006), 25\% of total indicators can be deleted to get the model fit, as such less than $20 \%$ of indicators were deleted. There are three criteria to assess the outer model which are Convergent Validity, Composite Reliability and Discriminant Validity (Latan \& Ramli, 2013). Indicators throughout the entire construct, the value of Convergent Validity is above 0.5 which are valid and acceptable. The minimal criterion of 0.7 is exceeded by all measurement elements for Composite Reliability (Sarstedt $e t$ al., 2014). Individual construct's square root AVE value is above 0.5 , thus the variables divergent validity is achieved. The HTMT result is greater than 0.85 , indicating that they are most likely measuring the same thing and that Discriminant Validity between constructs existed (Campbell \& Fiske, 1959).

Hair et al. (2011) claimed that the 5,000 subsamples were used to attain the significant levels using the consistent PLS bootstrapping option. The test results were obtained from testing the hypothesis with bootstrapping using statistical software Smart PLS 3.2.8. The test results are presented in Fig. 2 as below.

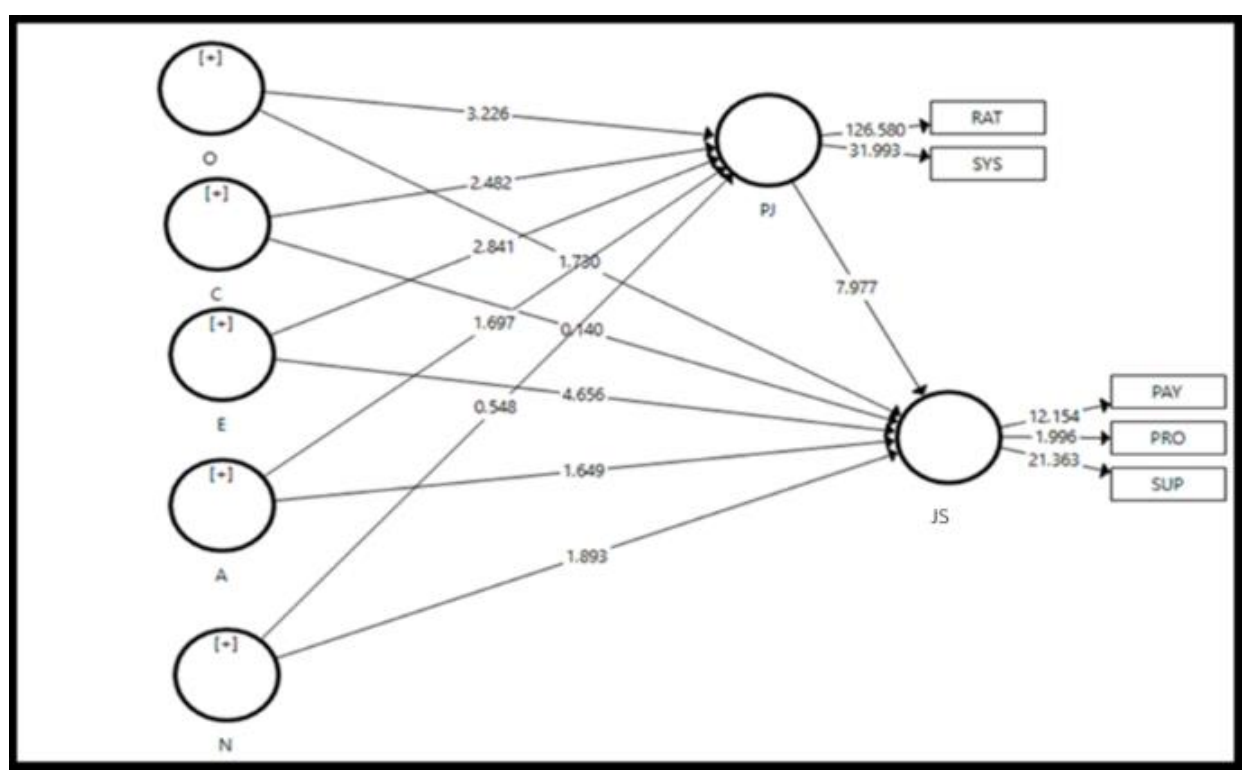

Fig. 2. T-value among the Dependent Variables (DV) and Independent Variables (IV)

Table III lists all the hypotheses from $\mathrm{H} 1$ through H6, as well as the T-statistics value for each hypothesis. The t-value is greater than 1.645 at $\mathrm{p}<0.05$ when the hypothesis is significant (Hair et al., 2011). We can deduct from the table that six hypotheses, H1, H3, H4, H5, and H6, are significant because the lower limit (LL) and upper limit (UL) are both positive, but $\mathrm{H} 2$ hypothesis, on the other hand, is not significant.

Base from the PLS output mediation hypothesis, only H7, H8, H9, and H10 is supported out of five mediation hypotheses. Preacher and Hayes (2008) also stated that the indirect effects 95 \& Boot CI: LL = 
0.070, $\mathrm{UL}=0.220$ for $\mathrm{H} 7, \mathrm{LL}=0.066 \mathrm{UL}=0.319$ for $\mathrm{H} 8, \mathrm{LL}=-0.320, \mathrm{UL}=-0.085$ for $\mathrm{H} 9$ and $\mathrm{LL}=$

$0.004, \mathrm{UL}=0.160$ for $\mathrm{H} 10$ hypothesis did not straddle a 0 in the middle, indicating mediation.

TABLE III: RESULTS OF HYPOTHESIS TESTING

\begin{tabular}{|c|c|c|c|c|c|c|c|c|c|c|}
\hline Hypothesis & $\begin{array}{c}\text { Beta } \\
\text { Value }\end{array}$ & $\begin{array}{c}\text { Std. } \\
\text { Error }\end{array}$ & $\begin{array}{c}\mathrm{T} \\
\text { Value }\end{array}$ & $\begin{array}{c}\mathrm{P} \\
\text { Value }\end{array}$ & UL & LL & $\mathrm{R} 2$ & $\mathrm{~F} 2$ & $\mathrm{Q}^{2}$ _predict & Decision \\
\hline H1:O->JS & 0.085 & 0.49 & 1.730 & 0.042 & 0.002 & 0.161 & 0.653 & 0.017 & 0.262 & Supported \\
\hline $\mathrm{H} 2: \mathrm{C}->\mathrm{JS}$ & -0.011 & 0.079 & 0.140 & 0.444 & -0.143 & 0.117 & & 0.000 & & Not Supported \\
\hline H3:E->JS & 0.364 & 0.078 & 4.656 & 0.000 & 0.234 & 0.487 & & 0.188 & & Supported \\
\hline H4:A-> JS & 0.095 & 0.058 & 1.649 & 0.050 & 0.000 & 0.189 & & 0.000 & & Supported \\
\hline H5:N-> JS & -0.311 & 0.164 & 1.893 & 0.029 & -0.516 & -0.015 & & 0.215 & & Supported \\
\hline H8:C->PJ ->JS & 0.190 & 0.077 & 2.463 & 0.007 & 0.066 & 0.319 & & & & Supported \\
\hline H9:E->PJ ->JS & -0.195 & 0.072 & 2.716 & 0.003 & -0.320 & -0.085 & & & & Supported \\
\hline H10:A->PJ ->JS & 0.0 .80 & 0.047 & 1.685 & 0.046 & 0.004 & 0.160 & & & & Supported \\
\hline H11:N->PJ->JS & 0.032 & 0.059 & 0.537 & 0.296 & -0.064 & 0.133 & & & & Not Supported \\
\hline
\end{tabular}

Hence, research result of the hypothesis as below.

H1: Openness to Experience $(O)$-> JS

Result shown a positive significant correlation $(\mathrm{t}=1.730, \mathrm{p}<0.05)$. Thus, $\mathrm{H} 1$ is accepted. This finding supported by previous research where researchers indicated being Openness to experiences was linked to job satisfaction (Cohrs et al., 2006).

H2: Conscientiousness (C)-> JS

Result shown there is no significant correlation $(t=0.140, \mathrm{p}>0.05)$. So, H2 is not accepted. This finding supported study conducted on UK employees which demonstrates that Conscientiousness is not a factor in job satisfaction (Bui, 2017).

H3: Extraversion (E) -> JS

Result shown a positive significant correlation $(\mathrm{t}=4.656, \mathrm{p}<0.05)$. Thus, H3 is accepted. This is conformed to recent study of which Extraversion is found to have a positive and significant relationship with manager's job satisfaction from multi-national companies in Philippines (Buama, 2019).

H4: Agreeableness (A)-> JS

Result shown a positive significant correlation $(\mathrm{t}=1.649, \mathrm{p}<0.05)$. Thus, H4 is accepted. This is consistent with previous findings that showed the most dominant dimension based on Big Five Personality for support staffs in UTM was Agreeableness (Ishak et al., 2018).

H5: Neuroticism (N)-> JS

Result shown a strong negative significant correlation $(\mathrm{t}=1.893, \mathrm{p}<0.05, \mathrm{~F} 2=0.215)$. Thus, H5 is accepted. The result also consistent with recent study which Neuroticism interacted with the corresponding mean personality, indicating that the fit between an individual's personality and the average personality of the occupation makes a difference in job satisfaction for this trait (Törnroos et al., 2019).

H6: Procedural Justice (PJ) -> JS

Result shown a positive significant correlation $(\mathrm{t}=7.977, \mathrm{p}<0.05)$. Thus, H5 is accepted. This is conforming study suggested that job satisfaction is more influenced by procedural justice than effective leadership (Elizabeth, 2018).

H7: Openness to Experience $(\mathrm{O})$-> PJ -> JS

Procedural justice mediated Openness to experience-job satisfaction correlation ( $\mathrm{p}<0.05)$. Thus, H7 is accepted. This is conforming to previous studies, which provided support for procedural justice's mediating function in the link between Openness to experience and job satisfaction. The ability of open-minded employees to create better relationships with their bosses is predicted to boost their decision-making authority and information access (Aryee \& Zhen, 2006).

H8: Conscientiousness $(C)$-> PJ -> JS

Procedural justice mediated Conscientiousness-job satisfaction correlation $(\mathrm{p}<0.05)$. Hence, H8 is accepted. This is conformed to previous study among 218 employees in insurance companies of Turkey which demonstrated that procedural Justice completely mediated the association between Conscientiousness and job satisfaction (Camgoz \& Karapinar, 2011).

H9: Extraversion (E) -> PJ -> JS

Procedural justice mediated Extraversion- job satisfaction correlation ( $\mathrm{p}<0.05)$. Hence, H9 is accepted. This is also like previous studies among 218 employees in insurance companies of Turkey which demonstrated that procedural justice mediated partially the correlations between Extraversion and job satisfaction (Camgoz \& Karapinar, 2011).

H10: Agreeableness (A) -> PJ -> JS

Procedural justice mediated Agreeableness-job satisfaction correlation ( $\mathrm{p}<0.05)$. Thus, H10 is accepted. This is also similar to previous studies among 218 employees in insurance companies of Turkey which 
demonstrated that the relationships between Agreeableness and job satisfaction were partially mediated by procedural justice (Camgoz \& Karapinar, 2011).

H11: Neuroticism (N) -> PJ -> JS

Procedural justice did not mediate correlation of Neuroticism-job satisfaction ( $p>0.05)$. Hence, H11 is not supported. This may be attributed to Neuroticism and job satisfaction have a strong association dimension of pay promotion and supervisor. Emotionally stable employees were expected to build better relationship with manager and focus on their pay and promotion opportunity because they are less threatened by certain scenarios. Findings suggested that job satisfaction was positively correlated with 300 workers from several textile manufacturers in Bangladesh were pay, supervisor and promotional opportunities (Muhammad \& Akhter, 2010). Procedural justice does not appear to mediate the relationship of personality traits on job satisfaction in this setting.

\section{CONClusions}

Our results detail several important theoretical contributions. First, this study finds that open, conscientious, extravert and agreeable employee perceived procedural justice as significant to give them job satisfaction. This shows that research that focuses only on personality traits decisions likely provides an incomplete assessment of predicting job satisfaction. Secondly, as previously mentioned, a few empirical studies such as Buama (2019), Ishak et al. (2018) and Kisten and Kluyts (2018) found a significant link between some personality traits and job satisfaction, but the number of personality traits tested as antecedents of job satisfaction was limited. By analyzing the Big-Five personality traits, this study examines a wide range of personality qualities as antecedents of job satisfaction. Third, and perhaps most importantly, this study contributes to a better understanding of how job satisfaction is enhanced by personality factors connected to job satisfaction. This study sheds some light on the association between each of the Big-Five personality traits and job satisfaction cognitions by completing a comprehensive analysis.

This research has several key consequences for firms' management teams. To begin with, personality has a significant influence in determining job satisfaction; therefore employers should pay close attention to these characteristics during the hiring process. Second, other features of organization, such as procedural justice, have been found to mediate personality traits, in predicting employee's job satisfaction. Thirdly, findings of the study become input to human resource strategic plan for existing front desk managers who should possess the right personality traits in handling different customers from all walks of life. Fourthly, this study may benefit hotel industry by shedding light on and contributing to a solution for high turnover among new staffs. Finally, it is also advantaging to hotel industries in Malaysia as the findings may lead to broader insight in enhancing employment by reducing turnover crisis in order to boost tourism industry in Visit Malaysia year.

There are some assumptions and considerations that should be noted in this study. First, respondent is assumed to have an isolated trait from the Big Five and each trait exists at different levels. Next, personality traits and job satisfaction are assumed as continuous variables. It will be translated that when a respondent scores high on one satisfied-related personality trait, simultaneously he or she will score very low on the other.

The survey is subjected to the bias of respondents. Hence $100 \%$ accuracy is not present. This was a cross sectional study which could not be generalized to other settings as data only collected from three-star hotels from central regions in Malaysia only. Next, usage of quantitative research method may cause some inconsistency of the result. The non-probability sampling strategy used in the deployment could have skewed the results. This study only considers procedural justice as mediating variable which is part of the organization justice and did not explore possibility of demographic factor as moderator. Finally, the Big Five personality traits are measured using the Big Five Inventory 44 items by John et al. (1991). More extensive tests like the Revised NEO Personality Inventory (John et al., 1991) may be more accurate.

The study's limitation should be addressed in future research. Research is suggested to expand to other geographical regions in Malaysia or other countries. A longitudinal study will be recommended or even explore other hotels at different star rating. Mix method research approach will be suggested to be used to further strengthen and to support findings of quantitative. A purposive sampling technique may be recommended to be used for future research. Future research could look at other mediating or moderating characteristics, such as leadership, empowerment, organizational culture, and others, which could be combined with dispositional variables to predict job satisfaction. Finally, future research should use McCrae and Costa's (John et al., 1991) Revised NEO personality questionnaire to investigate the connection between the Big-Five personality traits and job satisfaction. 
European Journal of Humanities and Social Sciences www.ej-social.org

\section{CONFLICT OF INTEREST}

Authors declare that they do not have any conflict of interest.

\section{REFERENCES}

Alam, A., \& Asim, M. (2019). Relationship Between Job Satisfaction and Turnover Intention. International Journal of Human Resource Studies, 9, 163.

Ali, I. (2018). Personality traits, individual innovativeness, and satisfaction with life. Journal of Innovation \& Knowledge, 4(10), 1016/j.jik.2017.11.002.

Aneika, L.S. (2011). The Influence of Openness to Experience and Organizational Justice on Creativity. Creativity Research Journal. 23(1), 9-23, DOI: 10.1080/10400419.2011.545707.

AON Heweiit China HCJ. (2016). Press release AON Heweiit APAC. http://www.thebest-truck.com/employee-turnover-rate-byindustry-in-malaysia/

Aryee, S., \& Zhen, X.C. (2006). Leader-member exchange in a Chinese context: Antecedents, the mediating role of psychological empowerment and outcomes. Journal of Business Research, 59(7),793-801.

Barrick, M.R., \& Mount, M.K. (1991). The Big Five Personality Dimensions and Job Performance A Meta-Analysis. Personnel Psychology, 44, 1-25.

Bennett, S., Hine, L., Mazerolle, L. (2019). Procedural Justice. Oxford Bibliographies.

Bindu, A., Dinesh A. M., Michael M. H. (2019). Personality and pay satisfaction: exploring the influence of organizational justice and gender in South Africa. The international journal of human resource management.

Bryman, A., \& Bell, E. (2015). Business Research Methods. (4th edition). Oxford: Oxford University Press.

Buama, C.A.C. (2019). Managers' Personality Preferences, Managerial Styles and Employee Satisfaction of Multi-National Companies: An Input to Human Resource Strategic Plan. PEOPLE. International Journal of Social Sciences, 5(1), $114-123$.

Bui, H.T. (2017). Big Five personality traits and job satisfaction: Evidence from a national sample. Journal of General Management, 42(3), 21-30. https://doi.org/10.1177/0306307016687990

Camgoz, S.M. \& Karapinar, P.B. (2011). Managing Job Satisfaction: The Mediating Effect of Procedural Fairness. International Journal of Business and Social Science, 2, 234-243.

Campbell, D. T., \& Fiske, D. W. (1959). Convergent and discriminant validation by the multitrait-multimethod matrix. Psychological Bulletin, 56(2), 81-105.

Cohrs, C, Abele, A.E, Dette, D.E. (2006). Integrating situational and dispositional determinants of job satisfaction: Findings from three samples of professionals. Journal of Psychology: Interdisciplinary and Applied, 140(4), 363-395.

Cohrs, C., Abele, A.E., Dette, D.E. (2006). Integrating situational and dispositional determinants of job satisfaction: Findings from three samples of professionals. Journal of Psychology: Interdisciplinary and Applied, 140(4), 363-395.

Elizabeth E. (2018). Automated Policing. Ohio State Journal of Criminal Law, 15, 559-63. https://papers.ssrn.com/sol3/papers.cfm?abstract_id=3150651.

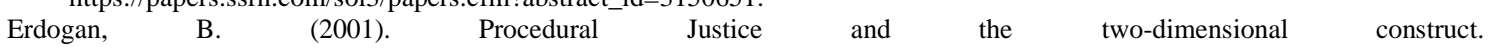

https://journals.sagepub.com/doi/abs/10.1177/0021886301372004
Golpayegan, M.A. (2017). Evaluating the Relation between Personality Properties with Job Satisfaction of the Staff. http://193.140.9.50/index.php/ilk/article/view/964

Heydarian, M., \& Abhar, S. (2011). Factors Contributing to Employee's Turnover Intention. SEGI Review, 4(2), 31-41.

Homans, G.C. (1961). Social behavior: Its elementary forms. Oxford, England: Harcourt, Brace.

Ishak A., Mahfar M., Yusof H. (2018). The Relationship between Big Five Personality and Job Satisfaction among Support Staff in UTM, Johor Campus. https://core.ac.uk/download/pdf/225547513.pdf

Ishak, A., Mahfar, M., Yusof, H. (2018). The Relationship between Big Five Personality and Job Satisfaction among Support Staff in UTM, Johor Campus.

John, O.P., Donahue, E.M., Kentle, R.L. (1991). The Big-Five Inventory-Version 4a and 54. Berkeley, CA: Berkeley Institute of Personality and Social Research, University of California.

Judge, T.A., \& Lanen, R.J. (2001). Dispositional affect and job satisfaction: A review and theoretical extension. Organizational Behavior and Human Decision Processes, 67.

Julie M., \& Jacqueline, K. (2017). The database of the predicts (projecting responses of ecoogical diversity in changing terrestrial systems) project. https://erepo.uef.fi/handle/123456789/4482

Karnica, T.A.P. (2016). The effect of employer brand dimensions on job satisfaction: gender as a moderator. Management Decision, 54(4), $854-886$.

Kharismasyah, A., Pratama, B., Bagis, F. (2017). Job Satisfaction as a mediator of justice perception towards organizational citizenship behavior. Benefit. Journal Management and Business, 2. 10.23917/benefit. v2i2.5485.

Kisten, P., \& Kluyts, H. (2018). An evaluation of personality traits associated with job satisfaction among South African anesthetists using the Big Five Inventory. Southern African Journal of Anaesthesia and Analgesia, 24(1), 9-15. DOI: $10.1080 / 22201181.2018 .1433986$.

Kottawatta, H. (2016). Big Five Personality on Job Satisfaction: Perspective of Sri Lankan Male and Female School Teachers. https://www.researchgate.net/profile/Hemantha-

Kottawatta/publication/327667688_Big_Five_Personality_on_Job_Satisfaction_Perspective_of_Sri_Lankan_Male_and_Femal e_School_Teachers/links/5b9cff7c92851ca9ed0b18b5/Big-Five-Personality-on-Job-Satisfaction-Perspective-of-Sri-LankanMale-and-Female-School-Teachers.pdf

Lambert, E.G., Edwards, C., Camp, S.D., Saylor, W.G. (2005). Here today, gone Tomorrow, back again the next day: Antecedents of correctional absenteeism. Journal of Criminal Justice, 33, 165-175.

Latan, H. \& Ramli, N.A. (2013). The Results of Partial Least Squares-Structural Equation Modelling Analyses (PLS-SEM). http://dx.doi.org/10.2139/ssrn.2364191

Loi, R., Yang, J.X., Diefendorff, J.M. (2009). Four-Factor Justice and Daily Job Satisfaction: A Multi-Level Investigation. Journal of Applied Psychology, 94, 770-781. http://dx.doi.org/10.1037/a0015714

McCrae, R R., \& Costa, P.T., Jr. (1991). The NEO Personality Inventory: Using the five-factor model in counselling. Journal of Counselling and Development, 69, 367-37.

Muhammad, I., \& Azhar, K. (2015). The Relationship of Big Five Personality Traits with Job Satisfaction Among Banking Employees. Journal of Applied Environmental and Biological Sciences, 5(5), 129-138.

Muhammad, N., \& Akhter, M. (2010). Supervision, Salary and Opportunities for Promotion as Related to Job Satisfaction. https://www.semanticscholar.org/paper/Supervision\%2C-Salary-and-Opportunities-for-Promotion-MuhammadAkhter/5376a1c7847860290e27042f90d0866ffd3ad3ac

Nadiri, H., \& Tanova, C. (2010). An investigation of the role of justice in turnover intentions, job satisfaction, and organizational 
European Journal of Humanities and Social Sciences www.ej-social.org

citizenship behavior in hospitality industry. International Journal of Hospitality Management, 33-41.

Ombudsman Western Australia (2019). http://www.ombudsman.wa.gov.au/Publications/Documents/guidelines/Procedural-fairnessguidelines.pdf

Rožman, B., Treven, S., Čančer, Vesna (2017). Motivation and Satisfaction of Employees in the Workplace. Business Systems Research, 8(2),14-25.

Sarstedt, M., Ringle, C., Smith, D., Reams, R., Hair, J. F. (2014), Partial least squares structural equation modelling (PLS-SEM): A useful tool for family business researchers. Journal of Family Business Strategy, 5(1), 105-115. https://EconPapers.repec.org/RePEc:eee:fambus:v:5:y:2014:i:1:p:105-115.

Seibert, S. E. \& Kramer, M. L. (2001). The Five Factor Model of personality and career success. Journal of Vocational Behavior, 58, $1-21$.

Sekaran, U., \& Bougie, R. (2010). Research methods for business: A skill-building approach. Chichester: J. Wiley \& Sons.

Shi, J., Lin, H., Wang, L., Wang, M. (2009). Linking the big five personality constructs to organizational justice. Social Behavior and Personality, 37, 209-222.

Singh, D., \& Amandeep, M. (2017). Impact of employee turnover on hotel industry- a study of selected hotels of New Delhi. International Journal of Research - Granthaalayah, 5(4), 153-158. https://doi.org/10.5281/zenodo.570181

Soto, C.J. (2018). Big Five personality traits. In M.H. Bornstein, M.E. Arterberry, K.L. Fingerman, J.E. Lansford (Eds.), The SAGE encyclopedia of lifespan human development (pp: 240-241). Thousand Oaks, CA: Sage.

Spector, P.E. (1985) Measurement of human service staff satisfaction: Development of the Job Satisfaction Survey. Am J Community Psychol.

Tett, R.P., \& Burnett, D.D. (2003). A personality trait-based interactionist model of job performance. Journal of Applied Psychology, $88,500-517$.

Tett, R.P., \& Guterman, H.A. (2000). Situation trait relevance, trait expression, and cross-situational consistency: Testing a principle of trait activation. Journal of Research in Personality, 34, 397-423.

Törnroos, M., Jokela, M., Hakulinen, C. (2019). The relationship between personality and job satisfaction across occupations. Personality and Individual Differences, 145, 82-88. https://doi.org/10.1016/j.paid.2019.03.027.

Wong H.M., \& Amalathas S.S. (2020). The Error Analysis for Enterprise Software Application Using Analytic Hierarchy Process and Supervised Learning: A Hybrid Approach on Root Cause Analysis. In: Silhavy R., Silhavy P., Prokopova Z. (Eds.) Software Engineering Perspectives in Intelligent Systems. CoMeSySo 2020. Advances in Intelligent Systems and Computing, vol 1295. Springer, Cham. https://doi.org/10.1007/978-3-030-63319-6_59.

Wong H.M., Amalathas S.S., Zitkova T. (2020). A Prescriptive Analytical Logic Model Incorporated with Analytic Hierarchy Process for Software Application Error Analysis. In: Silhavy R. (Eds.) Intelligent Algorithms in Software Engineering. CSOC 2020. Advances in Intelligent Systems and Computing, vol 1224. Springer, Cham. https://doi.org/10.1007/978-3-030-51965-0_1.

Wong, H.M., \& Amalathas, S.S. (2019). A New Approach Towards Developing a Prescriptive Analytical Logic Model for Software Application Error Analysis. In: Silhavy R., Silhavy P., Prokopova Z. (Eds.), Intelligent Systems Applications in Software Engineering. Advances in Intelligent Systems and Computing, vol 1046. Springer, Cham. https://doi.org/10.1007/978-3-03030329-7_24.

Worrell, T. (2004). School psychologists' job satisfaction: Ten years later [Unpublished doctoral dissertation]. Virginia Polytechnic Institute and State University.

Yamazaki, Y., \& Yoon, J. (2012). Fairness and job satisfaction of Japanese multinationals in Asia. Working Papers EMS_2012_05, Research Institute, International University of Japan.

Yildirim F., et al. (2015). The relationship between the five factor personality traits of workers and their job satisfaction: a study on five-star hotels in Alanya. 3rd Global conference on business, economics, management and tourism, 26-28 Nov 2015, Rome, Italy..

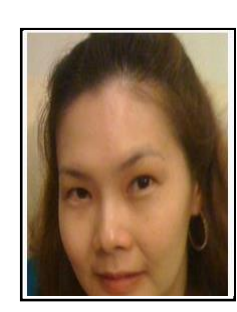

completion of $\mathrm{PhD}$

Tham Soot Yee is a final year PhD student in Business Administration at UNITAR International University, Malaysia. Her current study is to investigate the relationship of Big Five personality traits and job satisfaction, while examining organization procedural justice as mediator. Her research interest is a quantitative study among front desk managers of three-star hotels located in central regions of Malaysia. For her PhD thesis, she is working under the supervision of Dr. Rudzi Munap, as principal supervisor and Dr Athirah Mohd. Tan, as co-supervisor. She holds a master's degree in business computing from Charles Sturt University, Australia, and bachelor's degree in economics from Northern University Malaysia. By professional, she had more than 20 years of working experience in business operations field in several multi-national organizations such as Hewlett Packard, Ricoh, Fuji Xerox, and Yamaha Music. Her next thing to do on the bucket list is to go travelling and see the world after the

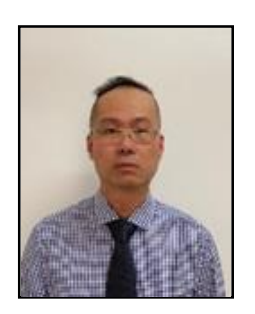

Hoo Meng Wong is a final year PhD student in Taylor's University, Malaysia. He holds two bachelor degrees and a master degree. The bachelor degrees are Bachelor of Science in Computer Science (awarded by La Trobe University, Melbourne, Australia), and Bachelor of Business (Hons) in Banking and Finance (awarded by Wawasan Open University, Malaysia). For the master degree, it is Master of Science in Technology Management (awarded by Staffordshire University, United Kingdom). Hoo Meng is new to publishing journal paper although he had started the PhD studies back in 2016. At that time, he was with UNITAR International University, Malaysia. The reason for him transferred to Taylor's University because his supervisor had decided to join Taylor's University as one of the outstanding universities in Malaysia. Google Scholar: https://scholar.google.com/citations?hl=en\&user=iNdrbakAAAAJ 